\section{Problems in Ireland ...}

SIR - In your leading article "What Brussels should do for research" (Nature 362,$93 ; 1993$ ) you emphasized the need to increase the quality, quantity and participation in science research in countries such as Ireland. Your article is indeed timely as it is likely that financial support by the Irish government for research will be significantly reduced from its already low level.

I believe that scientists would warmly welcome the development of new strategies that would address many of the problems that are in danger of causing major damage to the scientific base in Ireland. This had begun to develop significantly in the past few years in terms of quality. In addition, a number of new universities and tertiary institutes were established. However, if these and the well-established universities and institutes are to continue and improve, what is required is an increase in support, not a major reduction.

Ireland has a well developed educational system that supplies good candidates for science and technology courses. This is in no small measure due to the out-of-school science activities of organizations such as the Royal Dublin Society and the Aer Lingus Young Scientists Exhibition and many dedicated teachers. Hence, Irish Young Scientists have done remarkably well at international science competitions. At tertiary level, there is a variety of courses of a very high standard. However, the support for research, particularly basic research, is severely limited. This has implications for advanced training of students in techniques relevant to modern industrial processes, it severely limits the ability of lecturing staff to be fully up to date with new technologies and it limits the ability to provide 'state-of-the-art' technology and training at tertiary level for both indigenous and multinational companies. The argument is often made that what is required is applied research to deliver products and processes directly to industry. Undoubtedly, this approach is absolutely necessary but because technology advances and changes so rapidly, failure to keep up will give a very limited life to any industry. There are many examples where what was 'academic' a few years ago is now very much applied. What is required is a balance where basic and applied research co-exist and catalyse further developments.

It is also important to remember that where jobs are indeed a problem, as in Ireland, postgraduate research positions should be clearly seen as making a major contribution to employment - where else would employment cost so little and the employee undergo intensive train- ing? It is very good value for money.

What Brussels should do is to provide direct support for research students and equipment in the less advantaged areas provided they interact with major European collaborators. In this way all involved would benefit. Otherwise, there is a real danger of a one-way traffic whereby aspiring scientists will move to the well-developed centres and then will be unable to return to improve their countries of origin, due to the lack of positions and of research support. If this happens, surely the whole concept of a truly equal and united Europe will be merely hearsay.

\section{Richard O'Kennedy}

School of Biological Sciences,

Dublin City University,

Dublin 9, Ireland

\section{... and Spain}

SIR - In addition to the problems encountered by Spanish researchers in finding a post in Spain after they have obtained a doctorate in another country (Nature 306, 502; 1992 \& 361, 578; 1993), there is also the slowness of the procedure for obtaining recognition of their title. Although this document is an essential prerequisite for the competition for posts in universities and in the CSIC (Spanish Council for Scientific Research), it can be obtained only after a bureaucratic process that takes at least one year and sometimes more than two. During this period, researchers who have obtained their degrees abroad cannot be candidates for these posts and are therefore at an enormous disadvantage in relation to homegrown researchers.

Having applied in June 1991 for recognition of my doctorate, which I obtained in Paris, I presented my candidacy for a CSIC post as a palaeobotanist. I was accepted as a candidate - indeed, the only candidate - for this post, but in March 1992 the jury refused to let me take the examination owing to the absence of the document recognizing my title. Despite the decision of the president of the CSIC to readmit my candidacy, the jury, in June 1992, refused to examine me once again. In July I was readmitted a second time, having finally obtained recognition of my French doctorate after more than a year. Despite this, the new president of the CSIC, José Mato, decided in November to exclude me from the examination and to cancel the competition. As I was the only candidate, the post has been lost.

The opposition displayed by certain Spanish scientists towards the return to Spain of young researchers trained abroad often takes advantage - with the complicity of the administration - of protectionist bureaucratic mechanisms dating from the Franco period. The time wasted in awaiting recognition of their title puts a substantial block on these young researchers at the most critical point in their career.

Marla Fernanda Sánchez Goñi

University of Cambridge,

Department of Plant Sciences,

Subdepartment of Quaternary Research,

Downing Street,

Cambridge CB2 3EA, UK

\section{. . . and Italy}

SIR - It has already been reported that, contrary to official policy, the scientific merits of candidates for academic promotion in Italy are not given primary consideration by the members of the judging commission, so it often happens that a loser has a curriculum vitae (c.v.) clearly superior to that of a winner ${ }^{1}$. Unfortunately, it may also be superior not only to those of the winners but also to those of the commission. A recent experience of mine is a case in point.

I participated in a national competition called to fill eight positions of associate professor in gastroenterology ${ }^{2}$. A seven-member commission had the job of ranking the candidates on the basis of their scientific qualifications and on their performance at an oral examination consisting of a discussion of their scientific work and an academic lesson. Before the examination, one of the commissioners told me that I would not be one of the winners because the positions had already been assigned to others who were, for the most part, assistants to the various commission members. As forewarned, I did not win, despite a good oral presentation and the best c.v. of all the candidates. One of the most disturbing aspects of this experience, which I think merits emphasis, is that my c.v., rated on the basis of the number of publications (Medline Data Base), on the number of citations in the literature (Science Citation Index), and the impact factor $^{1}$, was not only better than that of any of the winners but also of those of the commission members as well. By bringing still more evidence to light, I hope I have made some contribution towards reforming an outmoded and unfair system, one that permits arrogant and unscrupulous commissioners to do as they please.

\section{Luclo Gullo}

First Medical Clinic,

University of Bologna,

Bologna, Italy

1. Gaetani, G. F. \& Ferraris, A. M. Nature 353, 10 (1991)

2. Gazzetta Ufficiale della Repubblica Italiana n. 70 -bis, 4 settembre 1990, e n. 47-bis, 14 giugno 1991. 